Boise State University

ScholarWorks

Organizational Performance and Workplace

Learning Faculty Publications and

Department of Organizational Performance and

Presentations

Workplace Learning

$9-2020$

\title{
Growth Mindset for Human Resource Development: A Scoping Review of the Literature with Recommended Interventions
}

Soo Jeoung Han

Boise State University

Vicki Stieha

Boise State University

Han, S.J. \& Stieha, V. "Growth Mindset for Human Resource Development: A Scoping Review of the Literature with Recommended Interventions", Human Resource Development Review. Advance online publication. Copyright (c) 2020, SAGE. Reprinted by permission of SAGE Publications. Doi: 10.1177/1534484320939739 
This is an author-produced, peer-reviewed version of this article. The final, definitive version of this document can be found online at Human

Resource Development Review, published by SAGE. Copyright restrictions may apply. doi: 10.1177/1534484320939739

\title{
Growth Mindset for Human Resource Development: A Scoping Review of the Literature with Recommended Interventions
}

\author{
Soo Jeoung Han \\ Boise State University
}

\author{
Vicki Stieha \\ Boise State University
}

\begin{abstract}
Although the concept of mindsets is relatively ubiquitous in the common press and well-studied in the education literature, the idea of a growth mindset, rooted in implicit theories (Dweck \& Leggett, 1988), is less represented in human resource development (HRD) scholarly literature. Given that absence, the purpose of this paper is to investigate the effects of a growth mindset on HRD outcomes. To achieve this purpose, we conducted a scoping literature review including research conducted globally and in a wide variety of organizations. Based on the empirical findings, we discuss three categories of HRD outcomes of mindsets: (a) individual-level outcomes (e.g., work engagement, creativity, task performance, job satisfaction), (b) dyadiclevel outcomes (e.g., supervisor-employee relationship and conflict resolution), and (c) organizational-level outcomes (e.g., organizational citizenship behaviors and organizational growth mindset). We synthesize several suggestions for growth mindset interventions emphasizing career development, training and development, and organizational development for HRD practitioners. Research implications and future research suggestions for HRD scholars are presented.
\end{abstract}

Keywords: growth mindset, interventions for HRD, implicit person theory

\section{Introduction}

Organizations seeking a competitive edge are increasingly turning their attention to ways they can bolster employee learning and performance for greater innovation, creativity, and collaboration. To achieve these goals, it is essential to invite employees to "experiment" and to "learn from mistakes" as they "search together for innovative solutions" (Hüther, 2016, p. 40). However, not everyone is psychologically prepared to welcome learning from mistakes. Those who are prepared may be described as having a "growth mindset" and organizations that foster growth mindsets among their staff are often identified as progressive and innovative (Dweck, 2006; Dweck, Murphy, Chatman, Kray, \& Delaney, 2014a).

Human Resource Development (HRD) scholars have focused on building research and practice to develop individuals' career and professional effectiveness within organizations. Building growth mindsets in employees and organizations is consistent with HRD research and practice tradition; HRD integrates "training and development, career development, and organizational development to improve individual and organizational effectiveness" (McLagan, 1989, p. 52). As HRD scholars and practitioners are committed to learning and helping people and organizations to improve their performance, it is fruitful to explore other disciplines and to mine potential implications for HRD (Swanson, 2001).

HRD, which historically has adopted psychological theories, can benefit through the introduction of growth mindset, a concept introduced in this paper. Initially coined by Carol Dweck, a growth mindset, which is defined as people's lay beliefs about human attributes (Dweck, 2012; French, 2016), is based on implicit person theory (IPT). This theory, originating from psychological research, embodies the belief in the potential to develop intellect, to increase talent, and to adjust moral understandings (Dweck, 2006). Compared to the concept of a fixed mindset (the idea that individuals are born with a fixed level of a particular human attribute), a growth mindset (the idea that individuals can develop that human attribute) has been found to positively impact individual performance, dyadic relationships, and organizational performance. This conceptual framing of mindsets has pertinence in learning design and organizational performance, yet, despite its popularity, there have not been reviews about this concept conducted in HRD scholarly work. 
This is an author-produced, peer-reviewed version of this article. The final, definitive version of this document can be found online at Human Resource Development Review, published by SAGE. Copyright restrictions may apply. doi: 10.1177/1534484320939739

\section{Problem Statement and Significance}

Given this gap, we assert that it is essential to conduct a comprehensive review of the ways Dweck's conception of a growth mindset is being empirically investigated in conjunction with HRD related topics. Based on a recent trend review of HRD scholarly literature, HRD researchers will continue to produce a variety of themes and boundarycrossing topics while shaping a new identity of HRD (Removed for review, 2017). A growth mindset is complementary with other timely lines of inquiry drawn from psychology in the HRD field. Therefore, we reviewed scholarly literature referencing mindset research in different disciplines, such as psychology, management, communication, and education. We believe this body of research is thought-provoking and can inform future HRD research and practice.

Mindset theory has been studied most extensively in primary, secondary, and tertiary educational settings and, to a lesser extent, in management studies, and adult learning. Most empirical studies that build on the original identification of mindset theory focus on the effects of teaching learners that intelligence can be developed, but the majority of findings are related to academic outcomes, such as mathematics performance, reading test scores, and higher grades (Aronson, Fried, \& Good, 2002; Blackwell, Trzesniewski, \& Dweck, 2007). Interventions with student populations follow a general protocol in which the population is introduced to the concept that people believe these attributes are unchangeable (fixed) or that they can be developed through learning and experience (growth). These interventions often then measure participants' responses to a mindset scale before and after the intervention. Reported findings have correlated higher scores on the mindset scale with positive academic outcomes including increases in test scores and higher grade point averages (e.g. Aronson et al., 2002; Blackwell et al., 2007). Based on these results, scholars and practitioners can ask if mindset theory is applicable to adults and workplace settings, and if so, how.

Recent interest in growth mindset in the common press may be fueling curiosity among researchers in a broader range of disciplines with findings that are pertinent to HRD researchers and practitioners. Studies have examined a growth mindset as one of the factors that enhance workplace engagement (Caniëls, Semeijn, \& Renders, 2018), employee productivity (Keating \& Heslin, 2015), mentoring (Gregory \& Levy, 2011), leadership (Gutshall, 2013; Heslin, Latham, \& Vandewalle, 2005; Kam, Risavy, Perunovic, \& Plant, 2014; Özduran \& Tanova, 2017), willpower (Dweck, 2012), openness to feedback (Forsythe \& Johnson, 2017), self-awareness (Ravenscroft, Waymire, \& West, 2012), and creativity (Hass, Katz-Buonincontro, \& Reiter-Palmon, 2016) in organizations. HRD researchers and practitioners may be interested in the findings shared by Kam et al. (2014), whose study demonstrated that employees' assumptions of their managers' mindset impact workplace performance. Not only does the literature demonstrate individual gains from a growth mindset, workplace leaders' growth mindsets have been described to impact the overall organization through their influence on employees (Dweck, 2006; Özduran \& Tanova, 2017) and we are starting to see references to organizational or collective mindsets (e.g. Dweck et al., 2014a; Hanson, Bangert, \& Ruff, 2016) that are pertinent to HRD research and practice.

In addition, the view of "learning" vs. "performance" is a central discussion in the HRD literature (Barrie \& Pace, 1999; Removed for review, 2017; Kuchinke, 1998). In particular, HRD’s interest in performance via goal orientation can be informed by empirical work related to a growth mindset. Elliott and Dweck's early work in goal orientation (1988) has been cited in the HRD literature in two empirical studies (Ismail, 2016; Moon, Choi, \& Jung, 2012). These studies draw upon Dweck's work to explore how a learning goal orientation focuses on improving one's capabilities, whereas a performance goal orientation seeks to demonstrate competencies and gain recognition for accomplishments. However, there are no citations in HRD specific journals for empirical work directly investigating HRD outcomes or variables using the conceptual lens of mindset theory. It is our position that the HRD field can benefit from findings regarding growth and fixed mindsets that have been conducted in other disciplines, hence a scoping review will support such further investigation.

\section{Research Purpose}

Our interest is in discerning the ways that mindset theory is being investigated in related disciplines with application to the HRD field. Therefore, the purpose of this study is to examine how researchers from a variety of fields apply the mindset theoretical framework to HRD related variables and outcomes at individual level, dyadic level, and organizational levels. Our analysis of the findings seeks to clearly delineate the HRD variables that can be further investigated and the methods that are recommended based upon this body of literature. For practitioners, we have 
This is an author-produced, peer-reviewed version of this article. The final, definitive version of this document can be found online at Human Resource Development Review, published by SAGE. Copyright restrictions may apply. doi: 10.1177/1534484320939739

suggested evidence based HRD interventions that are aligned with the findings of the selected articles. Our focus is on adult employees and published empirical evidence. Prior to presenting our findings, we situate our discussion in the literature explaining the theoretical framework for growth and fixed mindsets.

\section{Conceptual Framework}

In this section, we provide an overview of growth and fixed mindsets relative to workplace learning and development and how mindsets are relevant to HRD.

\section{Theoretical Framework for Growth and Fixed Mindsets}

Mindset theory emerged from Dweck and associates' early work seeking to understand the patterns of behavior connected to motivation. Particularly, the foundational work sought to model the underlying psychology for "motivational processes" and the findings exposed a model explaining how a person's idea of their own intelligence plays into their goal orientation (Dweck \& Leggett, 1988, p. 256). Mindset theory, clinically defined as "implicit person theory," conceptualizes a person's beliefs in their own abilities and attributes as either malleable or not. Those who adopt a view of traits as malleable are described as "incremental" theorists and those who hold the view that traits or attributes are immutable are described as "entity” theorists (Chiu, Hong, \& Dweck, 1997; Dweck \& Leggett, 1988). As this earlier psychological research moved from lab-based studies into discussions with lay people, Dweck described implicit theories of human attributes rebranding incremental and entity theories as "growth and fixed mindsets" (Dweck, 2000, 2006). Hence, a growth mindset is based on the belief that one's skills, strengths, and abilities can be refined through effort and determination. A person with a fixed mindset considers skills, strengths, and abilities as immutable and, as a result, tends to avoid new experiences, preferring tasks that they are confident they can master. In addition to these definitions, Dweck and others continued to develop and refine instruments designed to measure people's attributional beliefs about ability as a scale that identifies a spectrum from fixed mindset to growth mindset (Dweck, 2006). The theory has since been applied to a broad set of human attributes including intellect, values, and talent and characterizes how a learner views and approaches new information.

Table 1

Mindsets and Implicit Person Theory

\begin{tabular}{lll}
\hline Mindsets & Implicit Person Theory & Definition \\
\hline Growth mindset & Incremental theory & Belief that one’s skills, strengths, and abilities can \\
& be refined through effort and determination. \\
\hline Fixed mindset & Entity theory & Belief that one’s skills, strengths, and abilities are \\
& innate and immutable, or only change slightly. \\
\hline
\end{tabular}

Although the term mindset is used colloquially and has been conceptualized based on a variety of disciplinary traditions (French, 2016), in this paper we will use the term mindset specifically to refer to the implicit theories of the self and others as we have defined it above in Table 1. Additionally, as the terms growth mindset (incremental theory) and fixed mindset (entity theory) have been defined as opposite ends of the same construct, we understand that when researchers discuss growth mindset theory in isolation and cite one or more of the foundational studies in Dweck's body of scholarship, they too are referencing a portion of the same spectrum.

In addition to measuring mindset, the body of research has demonstrated that a growth mindset can be primed or activated through positive cases, suggestions, and selected keywords. Dweck's now internationally famous TED Talk as well as her popular press book (Dweck, 2006) demonstrates the relatively simple moves that people can implement in their relationships with others and themselves to shift toward a growth mindset. Empirical work (e.g. Chiu et al., 1997; Rattan \& Dweck, 2018) details the classic experimental design approach used in psychology to activate mindsets. 
This is an author-produced, peer-reviewed version of this article. The final, definitive version of this document can be found online at Human

Resource Development Review, published by SAGE. Copyright restrictions may apply. doi: 10.1177/1534484320939739

\section{HRD and Mindset}

In this section, we will discuss how mindset theories can be applied to the field of HRD. Beyond the disciplines of psychology and elementary education, where mindset research has its foundation, many researchers have expanded upon the work of Dweck and her colleagues. Researchers have investigated the characteristics of growth and fixed mindsets and found several themes. Based on the summary of growth mindset research, the attributes of mindsets include: learning from mistakes (Aditomo, 2015; Lee, Heeter, Magerko, \& Medler, 2012), accepting feedback and criticism (Forsythe \& Johnson, 2017; Pennington \& Heim, 2016), and perseverance (Dweck, Walton, \& Cohen, 2014b). Studies demonstrated specific performance related behaviors resulting from mindset activation; for example, Lee et al. (2012) found that growth mindset gamers performed better than fixed mindset players as their mistakes did not affect their attention to the game. Forsythe and Johnson (2017) found that a growth mindset affected individuals' positive perceptions of feedback that they received.

One aspect of mindsets that is of particular importance to HRD is goal orientation. Mastery goal orientation, associated with a growth mindset, has been correlated with willingness to persist toward a challenging academic task while those whose mindset was identified as fixed were more likely to select performance goals (Elliott \& Dweck, 1988). Similar lines of inquiry have established mastery goal orientation as supportive of adults’ persistence in learning (Ong, 2014).

Self-efficacy is also related to mindset and goal-orientation. As Wood, Atkins, and Tabernero assert, "the question of how people cope with the cognitive demands of complex tasks is a central motivational issue in modern work organizations" (2000, p. 431). In testing the association between self-efficacy and mindset theory, findings suggest that complex task performance is moderated by adults' sense of their ability as growth or fixed; those with a growth mindset were more likely to outperform their fixed-minded business management peers on a group-management challenge (Tabernero \& Wood, 1999). Dweck (2006) discusses the work of Wood and others, describing the connection between the growth mindset and well-known corporate leaders' successes. These findings highlight need to investigate the relationship between the growth mindset and HRD related variables and outcomes.

Finally, in our discussion we will speak more about the ways that growth mindset findings can serve organizations to achieve desirable HRD outcomes. When it comes to HRD interventions, the focus of development can vary from individual skills development to relationship building and organizational system change (Day \& Harrison, 2007). We structure our discussion providing specific strategies designed to induce changes (Garcia, 2007).

\section{Methods}

To examine the effects of growth mindset theory in organizational settings, we reviewed the scholarly literature and identified empirical studies linking a growth mindset and HRD related variables and outcomes. We have chosen a scoping review method as it involves multiple rounds of structured research rather than a single search and focuses on the breadth of coverage of the literature conducted on a topic (Rumrill, Fitzgerald, \& Merchant, 2010). While resembling a systematic review, we have not systematically evaluated the quality of the studies considered in the review. Rather, our purpose is to offer a careful synthesis of relevant studies and summarize those which consider HRD related variables and outcomes as we believe this literature is pertinent to our work in performance and development.

\section{Search Process and Selection Criteria}

Our first review of the literature was conducted in 2017. We developed and tested search terms and identified viable databases through multiple iterations for our search with the assistance of our research librarian. The resulting Boolean search string included "growth mindset” AND (employee OR organization OR workplace OR "higher education" OR college OR university) NOT (elementary OR K-12 OR K12 OR child*) for each database. "Growth mindset” versus the more generic, "mindset” sought to focus on studies specifically about growth mindset theory (Dweck, 2006). Although researchers do use the terms, "implicit person theory” and "implicit theory of intelligence," our research demonstrated that empirical studies either exclusively referenced "growth mindset" or did so in addition to the original terminology. We included ("higher education” OR college OR university) to collect HRD related studies conducted in tertiary organizations and by university-based researchers. We established limiters including: a) published in peerreviewed journals in English, b) full text, c) published between 1993 and 2017, and d) empirical studies examining the effects of growth and fixed mindsets in 11 databases. A 1993 start date captures the citations of Dweck's early work on implicit theories of intelligence. 
This is an author-produced, peer-reviewed version of this article. The final, definitive version of this document can be found online at Human Resource Development Review, published by SAGE. Copyright restrictions may apply. doi: 10.1177/1534484320939739

Following a review of an earlier draft of this article, we updated our search to add 2018-2019 and reconsidered the rationale for including studies conducted in higher education or tertiary education settings as we explain below. We also directly searched in Human Resource Development Quarterly, Human Resources Development International, Human Resources Development Review, and Advances in Developing Human Resources using our Boolean string as recently published articles in these journals were not indexed in our available databases.

After removing duplicates, our combined search included 177 articles. The authors conducted an independent first screening of titles, abstracts, and scanned the articles for the inclusion and exclusion criteria, verifying our conclusions with one another. As our intention is to align this analysis closely with the interests and concerns of HRD practitioners and researchers, we culled our findings removing studies focusing on college student populations and outcomes. While initially we deemed higher education settings relevant to professional workforce preparation, upon final review, we found many were not directly applicable to HRD outcomes.

The resulting findings in the databases included (number of studies in parenthesis): ABI/Inform Collection (21), Academic Search Premier (52), Business Source Premier (9), Communication Source (1), Education Research Complete (20), PsycArticles (7), PsycINFO (24), ERIC (16), JSTOR (5), Web of Science (17), HRD Journal sites (3). Our revised limiters guided our final review of the resulting literature, and we removed those not meeting the following inclusion criteria: a) published in peer reviewed journals in English, b) full text, c) empirical research article, d) focusing on employees or adult human development, e) citing Dweck (implicit person theory, implicit theories of intelligence, or growth mindset), f) measuring a growth mindset consistent with Dweck's definition, and g) measuring HRD related variables.

\section{$\underline{\text { Review Procedures }}$}

We reached consensus on 12 articles that are highly pertinent to the HRD field which have empirically investigated a growth mindset as an antecedent or outcome related to HRD variables. While relevant to the HRD field, all of the articles were published in journals external to the HRD field: Career Development International, Current Directions in Psychological Science, Frontiers in Pediatrics, International Journal of Contemporary Hospitality Management, International Journal of Offender Therapy and Comparative Criminology, Journal of Applied Psychology, Journal of Educational Issues, Motivation Science, and Psychology in the Schools, Psychology of Aesthetics, Creativity, and the Arts. In the findings section below, we analyze the applicability of these findings and the implications of this body of research for HRD researchers and practitioners. We also discuss the research methods reported in the final set of articles included, although, as previously stated, we have not systematically evaluated those research methods. We contend, however, that the ways in which researchers have measured growth and fixed mindset is pertinent our findings and can be useful in future inquiry.

\section{Findings}

This study examines how researchers may apply the mindset theoretical framework to HRD related outcomes, such as work engagement, job performance, and employee relationships (Tharenou, Saks, \& Moore, 2007). In our analysis of the research meeting the criteria for this review, we identified three categories of HRD outcomes that have been empirically investigated using mindset theory. First, we synthesize the findings relative to three categories of HRD outcomes of mindsets: (a) individual-level outcomes (e.g., employee motivation, work engagement, and creativity), (b) dyadic-level outcomes (e.g., supervisor-employee relationships, coaching, and conflict resolution), and (c) organizational-level outcomes (e.g., organizational citizenship behaviors and school growth mindset). Some of the studies offer results in multiple HRD outcome levels (Day \& Harrison, 2007), hence the findings of these studies will be discussed according to each outcome level separately. Following the discussion of the HRD outcomes, we discuss the way that mindset theory is applied in the various studies, research methods details, and research settings. These findings are summarized in Table 2.

\section{Individual-Level Outcomes of Mindsets}

We found that individuals' growth mindsets greatly influence their behaviors within the workplace. A belief that one can improve their abilities can support individual-level outcomes, such as higher work engagement (Caniëls et al., 2018; Zeng, Chen, Cheung, Hoi, \& Pen, 2019), improved task performance (Cutumisu, Brown, Fray, \& Schmolzer, 2018), creative activities (Karwowski, Czerwonka, Lebuda, Jankowska, \& Gajda, 2019), and workplace satisfaction (Rattan \& Dweck, 2018). Regarding work engagement, individuals' growth mindsets have been shown to increase the 
This is an author-produced, peer-reviewed version of this article. The final, definitive version of this document can be found online at Human Resource Development Review, published by SAGE. Copyright restrictions may apply. doi: 10.1177/1534484320939739

motivation and determination of Chinese teachers to have a high level of work engagement (Zeng et al., 2019). Additionally, Zeng et al., (2019) found that well-being and perseverance of teachers' efforts could partially mediate the relationship between teachers' growth mindset and work engagement. Caniëls et al. (2018), investigating leadership in a Dutch high-tech organization, found that a growth mindset is critical for employees because it interacts with a transformational leadership style and has a positive impact on subordinates' level of engagement.

A range of task performance improvements are demonstrated as positively correlated with a growth mindset when researchers tested mindset theory interventions. These research protocols include priming or activating a growth or fixed mindset by exposing the participant to a case or scenario and then asking them to respond to questions about the case (e.g. Cutumisu et al., 2018; Karwowski et al., 2019). In particular, Cutumisu et al. (2018) found that neonatal resuscitation training is more useful for those with a growth mindset, and Karwowski et al. (2019) demonstrate that encouraging those willing to engage and put effort into creative activities leads to an increased growth mindset for creativity.

In addition to increasing participants' understanding about the potential benefits of a growth mindset, studies have also explored the limiting impact of a fixed mindset for individuals' ability to overcome obstacles. In particular, a fixed mindset was correlated to participants' reluctance to act on new entrepreneurial ideas in Keena and Simmons (2015) study involving incarcerated individuals who were preparing to be released from prison. Conversely, a growth mindset intervention contributed to a change in their performance ability beliefs. Finally, minorities and women with a growth mindset experienced an increased sense of well-being and belonging in a workplace simulation when they proactively addressed prejudice (Rattan \& Dweck, 2018). In addition to these studies examining the relationship between a person's level of growth mindset and other HRD related outcomes, researchers have investigated a variety of dyadic type outcomes in relation to mindset theory, which will be discussed in the next section.

\section{Dyadic-Level Outcomes of Mindsets}

One's growth or fixed mindset can impact other people's behavior and these mindsets can lead to team-level outcomes in the workplace. Mindset researchers have found that managers or employees' growth mindsets positively correlate to dyadic-level outcomes, such as improved relationships based on feedback and coaching (Gutshall, 2013; Özduran \& Tanova, 2017; Rattan \& Dweck, 2018; Shapcott \& Carr, 2019) and positive influence of managers on their teams (Caniëls et al., 2018; Heslin \& VandeWalle, 2008; Wang, Owens, Li, \& Shi, 2018). Managers or leaders’ mindset can influence others' behaviors. For example, Gutshall (2013) found that instructors who believe that ability is malleable and have a growth mindset are also likely to believe that the learners' abilities are malleable as well. A similar oneto-many relationship between an individual's mindset and that of subordinates' mindset is investigated by Özduran and Tanova (2017). In their study, which is conducted in the hospitality industry in North Cyprus, the authors linked the growth mindset of a manager and their coaching behaviors with increased organizational citizenship behaviors of subordinates. Understanding that motivation can be undermined by negative relational contexts, Rattan and Dweck (2018) primed minority participants who had experienced prejudice in the workplace with a growth mindset. After this growth mindset intervention, the participant would more confidently confront perpetrators of prejudice, positively impacting the relationship, and fostering a more positive workplace outlook.

Several dyadic-level studies examined the negative impact of fixed mindsets. Leader-subordinate relationships, another important HRD variable, have been illuminated through growth mindset theory research. For example, fixed mindset managers were less likely to recognize the extent to which the employee's performance had improved, and six weeks after receiving the intervention, these managers changed their perceptions and provided employees with more coaching suggestions (Heslin \& VandeWalle, 2008). In a similar vein, the coaches' mindset about their athletes' abilities is correlated with the behaviors the coaches demonstrate. Particularly, coaches' prejudice toward women's golf ability is correlated with negative feedback, resulting in lower player motivation and decreased player performance (Shapcott \& Carr, 2019). The researchers found that priming growth mindset, however, effectively reduces coaches bias leading to an increased performance of athletes as well as the amount of participation in golf for recreational purposes. Another study noted that transformational leadership has shown to be more effective in the presence of employees with a growth mindset (Caniëls et al., 2018). The researchers suggested that the role of leaders is essential as it affects employees' work engagement level. Another study found that the growth mindset of a leader often shows an increase in humility in their behavior, which can impact relational and task performance of team members (Wang et al., 2018). 
This is an author-produced, peer-reviewed version of this article. The final, definitive version of this document can be found online at Human

Resource Development Review, published by SAGE. Copyright restrictions may apply. doi: 10.1177/1534484320939739

\section{Organizational-Level Outcomes of Mindsets}

In the section above, we discussed dyadic relationships and HRD outcomes investigated using mindset theory. Although fewer in number, organizational-level outcomes have also been examined through the lens of mindset theory. These studies are generally examining one-to-many relationships that are impacted by leadership, communication, organizational behaviors, and collaboration. For instance, studies have found that workplace leaders' growth mindsets have been demonstrated to impact the overall organization through their influence on employees (Özduran \& Tanova, 2017), and mindset researchers have begun to tie growth mindsets into organizational or collective outcomes (Hanson et al., 2016). Organizational-level outcomes are related to cultural and system variables, such as creating a culture of organizational learning and increasing collective efforts for the organization's improved overall performance. For example, one study found that managers with higher growth mindset levels demonstrated effective coaching behaviors that had a mediating effect on the organizational citizenship behaviors of their employees and led to higher levels of the organizational citizenship behaviors (Özduran \& Tanova, 2017). Similarly, Hanson et al. (2016) found that a growth mindset helps leaders and staff foster positive relationships, effective communication, and collaborative efforts. More specifically, they investigated the way that a principal's mindset impacted the school's growth mindset, which may apply to an organizational mindset. A "school growth mindset" is comprised of "common vision, sharing knowledge, support, and resources” (Blackwell, 2012, as cited in Hanson et al., 2016, p. 225). This conceptualization of an organizational mindset includes three subfactors: "collaborative planning, shared leadership, and open communication and support," and these findings suggest that a growth mindset can be expanded to organizationallevel outcomes (Hanson et al., 2016, p. 225).

Taken in their entirety, the included research studies are consistent with the following recommended HRD practices:

- Work engagement, performance on a target task, persistence of effort

- Ability to evaluate others' performance (perception that an evaluand's skills and abilities are malleable)

- Holding an organizational mindset or organizational citizenship behaviors

- Demonstrating cultural responsiveness and awareness of prejudice or stereotypes

- Value for creativity and entrepreneurship

- $\quad$ Effective leadership behaviors (humility)

Each of these HRD related outcomes are examined in at least one and are highlighted in Table 2, below. Also, in Table 2, we summarize the findings presented above including the focus of each study outcome, how the study addresses mindsets, and the specific research methods and settings. Column two indicates the level or levels of the HRD related outcomes. Following Table 2, we synthesize the research methods and study designs to guide future investigations for HRD researchers. 
Table 2

Summary of HRD-related Outcomes of Mindsets Investigated, Methods, and Settings of Mindset Research

\begin{tabular}{|c|c|c|c|c|}
\hline Authors & $\begin{array}{l}\text { HRD Level } \\
\text { Outcomes } \\
\text { (I) Individual, }(D) \\
\text { Dyadic, }(O) \\
\text { Organizational }\end{array}$ & $\begin{array}{l}\text { HRD-related Outcomes of Mindsets Investigated } \\
\text { (1) Focus; (2) How study addresses mindset to } \\
\text { HRD-related outcomes }\end{array}$ & $\begin{array}{l}\text { (1) Research design: Experimental } \\
\text { design, Quasi experimental, Case, } \\
\text { Survey, Qualitative } \\
\text { (2) Mindset as variable (3) Growth, } \\
\text { fixed, or both } \\
\text { (4) Methods details }\end{array}$ & $\begin{array}{l}\quad \text { Research } \\
\text { Settings } \\
\text { Organization } \\
\text { type(s) } \\
\text { (country/ies) }\end{array}$ \\
\hline $\begin{array}{l}\text { Caniëls, } \\
\text { Semeijn, \& } \\
\text { Renders, } 2018\end{array}$ & I, D & $\begin{array}{l}\text { (1) Examined the relationship between proactive } \\
\text { personality and work engagement; (2) Study findings } \\
\text { demonstrate a positive relationship between mindset } \\
\text { and employees' work engagement. }\end{array}$ & $\begin{array}{l}\text { (1) Survey; (2) Mindset as an } \\
\text { antecedent of work engagement. (3) } \\
\text { Growth mindset measured (4) Tests a } \\
\text { three-way model with proactive } \\
\text { personality interacting with a growth } \\
\text { mindset, moderated by transformational } \\
\text { leadership contributing to work } \\
\text { engagement. }\end{array}$ & $\begin{array}{l}\text { Corporate } \\
\text { (Netherlands) }\end{array}$ \\
\hline $\begin{array}{l}\text { Cutumisu, } \\
\text { Brown, Fray, \& } \\
\text { Schmolzer, } \\
2018\end{array}$ & $\mathrm{I}$ & $\begin{array}{l}\text { (1) Examined the moderating role of a growth mindset } \\
\text { for health care providers' performance on a target task } \\
\text { during and after a neonatal resuscitation training } \\
\text { program; (2) Study findings demonstrated higher } \\
\text { growth mindset is associated with better performance. }\end{array}$ & $\begin{array}{l}\text { (1) Quasi-experimental (2) Mindset as a } \\
\text { predictor variable (3) Growth mindset } \\
\text { measured (4) Growth mindset tested as } \\
\text { a predictor variable for performance on } \\
\text { a refresher training game. }\end{array}$ & $\begin{array}{l}\text { Hospital } \\
\text { simulation } \\
\text { training lab } \\
\text { (Canada) }\end{array}$ \\
\hline Gutshall, 2013 & $\mathrm{D}$ & $\begin{array}{l}\text { (1) Investigated instructors’ perceptions of malleability } \\
\text { of others' abilities given scenarios regarding learning } \\
\text { disabled students; (2) Findings show a positive } \\
\text { correlation between teacher’s mindset (fixed or } \\
\text { growth) regarding malleability of students' academic } \\
\text { ability regardless of learning disability. }\end{array}$ & $\begin{array}{l}\text { (1) Experimental design; (2) Mindset } \\
\text { was measured as a predictor variable for } \\
\text { stability of intelligence beliefs; (3) } \\
\text { Growth \& fixed mindset was measured; } \\
\text { (4) Experimental design with } 3 \text { item } \\
\text { fixed mindset scale and reverse scored } \\
\text { positive responses. Teachers randomly } \\
\text { assigned to read a student case followed } \\
\text { by beliefs about students' ability } \\
\text { questionnaire. }\end{array}$ & $\begin{array}{l}\text { Non-profit - } \\
\text { school teachers } \\
\text { (USA) }\end{array}$ \\
\hline $\begin{array}{l}\text { Hanson, } \\
\text { Bangert, \& } \\
\text { Ruff, } 2016\end{array}$ & $\mathrm{O}$ & $\begin{array}{l}\text { (1) Measured organizational mindset of professionals } \\
\text { relative to becoming more culturally responsive; }(2) \\
\text { associational research into leaders' openness to change, }\end{array}$ & $\begin{array}{l}\text { (1) Survey research; (2) Growth mindset } \\
\text { school (SGM) culture as organizational } \\
\text { application of mindset theory; (3) SGM } \\
\text { measured as outcome; (4) Correlational }\end{array}$ & $\begin{array}{l}\text { Non-profit } \\
\text { organization } \\
\text { (USA) }\end{array}$ \\
\hline
\end{tabular}


staff openness to change, work locus of control, and organization's growth mindset.

Heslin \&
VandeWalle,
2008

$\mathrm{D}$
2008
(1) Tested malleability of one person's perception of another person's interaction style as fixed or growth through an intervention; (2) Intervention primes a growth mindset.

\begin{tabular}{|c|c|c|}
\hline $\begin{array}{l}\text { Karwowski, } \\
\text { Czerwonka, } \\
\text { Lebuda, } \\
\text { Jankowska, \& } \\
\text { Gajda, } 2019\end{array}$ & I & $\begin{array}{l}\text { (1) Tested malleability of a growth mindset when } \\
\text { creativity is activated; (2) Creative mindset } \\
\text { (growth/fixed mindset about creativity abilities) is } \\
\text { primed through interventions about creative thoughts } \\
\text { and types of creativity. }\end{array}$ \\
\hline
\end{tabular}

Jankowska, \&
I

Simmons, 2015

\begin{tabular}{l}
\hline Özduran \& \\
Tanova, 2017
\end{tabular}

$\mathrm{D}, \mathrm{O}$
(1) Evaluated intervention designed to increase entrepreneurship behaviors; (2) Outcome of the intervention design is to foster entrepreneurial behavior informed by mindset theory.

\section{(1) Investigated organizational citizen behaviors (OCB)} relative to a growth mindset; (2) Measured leaders' growth mindset finding there is a group effect of managers' mindsets which mediates coaching behaviors and impacts the culture of a department or team.

\begin{tabular}{|c|c|c|}
\hline $\begin{array}{l}\text { Rattan \& } \\
\text { Dweck, } 2018\end{array}$ & $\mathrm{I}, \mathrm{D}$ & $\begin{array}{l}\text { (1) Studied prejudice in the workplace by priming for } \\
\text { with growth vs. fixed mindset relative to subsequent } \\
\text { workplace satisfaction and sense of belonging; (2) } \\
\text { Found when targets hold a growth mindset and }\end{array}$ \\
\hline
\end{tabular}

study: positive significant relationship among independent variables (principal openness to change, faculty openness to change, work locus of control). Multiple regression analysis supported IV's contribution to SGM.

$\begin{array}{ll}\text { (1) Experimental design; (2) Growth } & \text { Corporate } \\ \text { mindset informs intervention with } & \text { (USA) }\end{array}$
managers; (3) Growth mindset and fixed mindsets are discussed; (4) Minimal discussion of methods: Managers level of growth mindset predicted employee evaluations and the extent to which managers provided employee coaching. (1) Experimental design; (2) Growth mindset is an outcome measure when various creativity types are activated; (3) Creative mindset scale (Karwowski, 2014) is measured; (4) Creative growth mindset increases when primed with creative thoughts activity and decreases with eminent/artist creativity.

$\begin{array}{ll}\text { (1) Qualitative; (2) Growth mindset } & \text { Nonprofit } \\ \text { literature is integrated into the } & \text { (USA) }\end{array}$

Community sample (Poland) intervention and analyzed in narrative analysis; (3) Growth mindset coded; (4) Discussion of narrative analysis with description of participants' outcomes.

(1) Survey research; (2) Growth mindset is used as a predictor variable for OCB; (3) Growth and fixed mindset measured; (4) Multiple scales including validated 8-item mindset scale (Levy \& Dweck, 1998) as IV and OCB scales as the DV, coaching behavior rating as mediator variable.

$\begin{array}{ll}\text { (1) Experimental; (2) Growth mindset } & \text { Various (USA } \\ \text { as a predictor variable for positive } & \text { \& England) }\end{array}$

expectations following prejudice confrontation and positive workplace

\section{[note -} participants are

Industry (Turkey) prison inmates] 
confront perpetrators of prejudice, growth mindset participants experienced more positive workplace outlook.

Carr, 2019

$\mathrm{D}$

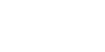

Li, \& Shi, 2018

D

D

(1) Explored leader humility and growth mindset theory; (2) Found a leader's growth mindset and relational identity were significantly related to leader humility.

(1) Exploring coaches' mindsets about athletes' ability and impact on player feedback, and whether coaches' mindsets about golf ability by gender are malleable; (2) Finds growth/fixed mindset about beliefs in player ability differs by player gender and impacts feedback response.

outlook; (3) Growth and fixed mindsets measured and manipulated; (4) Four studies three measured malleability beliefs of fundamental characteristics, beliefs, and personalities and outcome expectations. One manipulated mindset to prime a mindset condition.

(1) Two studies: survey research and quasi-experimental design; (2) Growth mindset as a predictor variable for gender differences in player ability, feedback type, and malleability of golf ability beliefs; (3) Growth-mindset items; (4) Validated 4-item growth mindset scale (study 1); theories of others' ability (Dweck, 2000) and priming to manipulate coach mindset. (1) Two studies: survey research; (2) Leaders growth mindset as an antecedent for leader-expressed humility; (3) 8-item "incremental theory of self" (Levy, Stroessner, \& Dweck, 1998); (4) Participant groups included leaders and subordinates. Leaders completed scale measuring growth/fixed mindset and follower's task performance while subordinates assessed leaders' humility, relational energy, their own emotional exhaustion, and perceived leader power.

\begin{tabular}{l}
\hline Zeng, Chen, \\
Cheung, Hoi, \& \\
Pen, 2019
\end{tabular}

Pen, 2019
(1) Investigated the relationship among growth mindset, work engagement, effort perseverance, and well-being for secondary educators; (2) Finds growth mindset predicted well-being and perseverance of effort contributing to a model to increase work engagement.

\section{(1) Survey research; (2) Teachers'}

growth mindset as a latent variable; (3)

Growth mindset scale measured; (4)

Structural equation modelling demonstrated significant and positive relationship between predictor variables (growth mindset, perseverance of effort, well-being) and the outcome variable (work engagement).
Professional

Golf

Associations

(USA and

United

Kingdom)

\section{Businesses}

(China)

Secondary
school teachers
(China)


This is an author-produced, peer-reviewed version of this article. The final, definitive version of this document can be found online at Human Resource Development Review, published by SAGE. Copyright restrictions may apply. doi: 10.1177/1534484320939739

\section{Exploring Mindset: Research Designs}

As discussed above, we have not evaluated the research methods employed in the body of literature reported in this study, however, we do provide a descriptive analysis of the methods employed. The research evaluated for this review is dominated by quantitative research methods, including six conducting survey research, four using experimental research design. One study employed qualitative methods and one used mixed methods. Other than in the qualitative research study (Keena \& Simmons, 2015) in which the authors design their intervention based on growth mindset findings and then code respondents' narrative responses to align with growth and fixed mindset constructs, the research in this scoping review has employed one of several growth and/or fixed mindset scales. The most cited scale for mindset theory includes three items strongly asserting belief in the malleability of traits signifying a growth mindset and three items strongly asserting the immutability of traits on a six-point Likert-type scale with no midpoint (Levy, Stroessner, and Dweck; 1998). Five studies used this instrument (Gutshall, 2013; Özduran \& Tanova, 2017; Rattan \& Dweck, 2018; Shapcott \& Carr, 2019; Wang et al., 2018). Others utilize five-point Likert-type scales ranging from strongly disagree to strongly disagree to provide consistency with scales for other measures in the study (e.g. Caniëls et al., 2018; Cutumisu et al., 2018). We note that Gutshall (2013) used the term "neutral mindset" to refer to a lack of clarity in mindset results falling between 3.1 and 3.9 on a six-point Likert-type scale, which is not consistent with the foundational mindset theory research (Levy et al., 1998).

Our review of the studies demonstrated that growth mindset scales, when modified to contextualize responses to the specific research question (e.g. leadership, golf ability), wording of the items retained fidelity to items validated repeatedly by Dweck and associates (e.g. Chiu et al., 1997; Levy et al., 1998). For example, "no matter how much golf ability women have, they can always change it quite a bit" (Shapcott \& Carr, 2019, p. 5) or "everyone is a certain kind of person, and there is not much that they can do to really change that” (Özduran \& Tanova, 2017, p. 595) track to "strong forms" of the growth mindset questions such as, "everyone, no matter who they are, can significantly change their basic characteristics" (Chiu et al., 1997, p. 22).

As indicated in Table 2, researchers in this body of literature have continued the methods employed in psychological research by activating a growth or fixed mindset through carefully scripted cases. Priming a mindset intervention has been demonstrated in this body of literature to provide lasting changes for a wide variety of individuals. These researchers found positive and lasting impact on participants from managers adopting growth mindset supportive appraisal strategies and coaching approaches for subordinates (Heslin \& VandeWalle, 2008) to community members experimentally activated to think about creativity through a growth mindset intervention (Karwowski et al., 2019).

\section{Discussion}

This study examined how researchers apply mindsets to HRD outcomes. Based on the findings, we offer the following HRD interventions and research implications for HRD. Finally, we share limitations and future HRD research suggestions.

\section{Suggested HRD Interventions of Mindsets}

To discuss the study findings regarding the effects of mindsets in workplaces, we have collected the HRD intervention ideas and suggestions from each selected study. We then coded each theme and summarized the interventions according to similar ideas. First, we have identified the type and subject matter for each kind of intervention. We also provide implementation recommendations for HRD practitioners drawn from the articles in this review.

Our findings suggested that mindsets are related to individual-level, dyadic-level, and organizational-level outcomes. In this section we do not delineate interventions by HRD level. As we discussed above, it is helpful to consider the interactions among individuals, teams, and the entire organization when strategizing effective organizational changes (Garcia, 2007). Given that human process-based interventions focus on changing behaviors by modifying individual attitudes, values, and work styles (Werner \& DeSimone, 2011), we understand interventions at one level can impact other levels. Thus, we provide holistic HRD interventions and suggest the focus can range from individual skills development to relationship building and organizational system change (Day \& Harrison, 2007). Our evidence-based recommendations highlight findings that a growth mindset can be developed by interventions, such as training, coaching, leadership development, recruiting, human resource practices, and performance evaluation systems. 
This is an author-produced, peer-reviewed version of this article. The final, definitive version of this document can be found online at Human Resource Development Review, published by SAGE. Copyright restrictions may apply. doi: 10.1177/1534484320939739

Training. Training activities focused on developing a wide variety of skills or behavior can be more effective if they focus first on employee development and begin by introducing the concept of growth and fixed mindsets (Keena \& Simmons, 2015; Özduran \& Tanova, 2017). The investment in time and effort is worthwhile as employees who have a growth mindset transfer knowledge more effectively from training interventions and improve their performance following training (Cutumisu et al., 2018; Özduran \& Tanova, 2017). Regardless of the skill, integrating growth mindset into training can help employees avoid perfectionism and value trial and error (Cutumisu et al., 2018) A welldesigned training integrating growth mindset may shape employees' openness to increasing their level of engagement in creative activities in the workplace (Karwowski et al., 2019).

For their part, management should embrace the belief that employees' new skill acquisition may require stepping outside of comfort zones (Özduran \& Tanova, 2017) and understnading that employees can grow and develop abiliites (Gutshall. Specific training activities for managers may include counter-attitudinal reflection where participants answer reflection questions about when and how they or people they know have changed their abilities and disposition over time (Heslin \& Vandewalle, 2008).

Coaching. Employee coaching is most effective if conducted with an intention to foster professional development and findings apply to both the coach and the coachee. As a fixed mindset hampers managers' acknowledgment of employee behavioral change and engagement in employee coaching (Heslin \& Vandewalle, 2008), changing employees and managers' mindsets to a growth mindset is vital for improving work engagement (Caniëls et al., 2018) and employee organizational citizenship behaviors (Özduran \& Tanova, 2017). Managers can be accountable for holding consistent feedback sessions as growth mindset oriented coaching feedback boosts employees' motivation and ability to perform (Shapcott \& Carr, 2019). Also, to encourage diversity in the organization, leaders can coach minority and women employees to safely confront negative expressions of prejudice at work and foster a growth mindset environment (Rattan \& Dweck, 2018).

Leadership Development. Leadership development programs need to emphasize not only technical or behavioral skills but also nurture a growth mindset to promote leader humility in organizations (Wang et al., 2018). Reflective practices to develop leaders' growth mindset beliefs can, in turn, influence employees' openness to organizational positive change (Hanson et al., 2016). The research has demonstrated that developing one type of leadership style (e.g., transformational leadership) is not a sole solution for every leader and employee as the employee mindset has to match to managers' leadership style. A transformational leadership style will be more effective with employees who have a growth mindset than those with fixed mindsets (Caniëls et al., 2018). Finally, managers' growth mindset beliefs regarding employee ability are consequential (Gutshall, 2013; Özduran \& Tanova, 2017).

Recruiting and HR Practice. Hiring and cultivating managers and staff with a growth mindset is critical for a growth mindset organization (Caniëls et al., 2018; Özduran \& Tanova, 2017) as they will be more likely to "believe in the possibility of change in human attributes over time [and will] exhibit better altruistic behaviors in the organization towards their colleagues (Özduran and Tanova, 2017, p. 600).

To reduce bias among employees at a workplace, HR practice and interventions should be designed to foster growth mindsets regarding employees regardless of gender or ethnicity and taking care to avoid isolating stereotyped groups (Shapcott \& Carr, 2019). Additionally, programs designed to address implicit bias are important as the biases held by leaders and mentors are evidenced in feedback, potentially working against retaining women and minority employees (Shapcott \& Carr, 2019). This finding is particularly critical in organizations or organizational units struggle with underrepresentation of women and minority employees among their staff and leadership.

Performance Evaluation System. HRD professionals can also help alleviate bias in evaluation systems by leveraging mindset theory related research. Understanding that managers with fixed mindsets may have blind spots when it comes to fairly evaluating employees. These managers are less likely to change either a positive or a negative initial impression when rating employees' performance (Heslin \& Vandewalle, 2008). Interventions including messages that employee skills can be improved with practice and helpful feedback (Heslin \& Vandewalle, 2008; Shapcott \& Carr, 2019) can reduce these managerial blind spots. Additionally, HRD professionals can design performance evaluation rubrics with written, verbal, and video-based cues and language that model growth mindset. Working on the performance evaluation system can reduce implicit bias and intentional prejudice in the workplace. It is important to be mindful of prior research that managers with a fixed mindset based on racial and ethnic identity may deny promotions to people if they do not want to work closely with them, despite the illegality of doing so (Dweck, 2012). 
This is an author-produced, peer-reviewed version of this article. The final, definitive version of this document can be found online at Human Resource Development Review, published by SAGE. Copyright restrictions may apply. doi: 10.1177/1534484320939739

\section{Implications for HRD Practice}

In sum, this literature review provides a list of research studies that have been conducted with employees in workplace settings. These studies can provide a starting point for HRD practitioners to use as they develop and document interventions encouraging individuals, dyads, and organizations to embrace a growth mindset. We found mindset theory research findings provide a well-substantiated evidence-base on which practitioners can design training and development, career development (e.g. performance evaluation, leadership, management), and organizational development (e.g. organizational culture, recruitment) efforts.

HRD practitioners interested in activating and measuring growth mindset can model instruments after those discussed in this body of literature. Given the range of contexts and adaptations represented in this body of literature, HRD practitioners may confidently adhere to the evidence based tenets of this body of mindset research by using strongly worded growth and fixed item stems (e.g. "everyone," "no matter who," "can always change") with a target belief in a human trait. Researchers should also measure findings to verify an altered instrument is reliable with their study population.

Based on empirical findings, having a growth mindset can improve an individual's professional development, leading to improved performance, enhanced creativity, and improved relationships. These attributes may enhance overall organizational performance and organizational learning. Therefore, HRD practitioners can focus on developing and cultivating a growth mindset in people, teams, and organizational cultures and systems. As we have discussed above, a growth mindset can be beneficial regardless of gender, ethnicity, or minority status. Still, for minoritized people facing stereotype threat or prejudice (e.g., minorities or women proactively addressing prejudice), cultivating a growth mindset primed to counter the threat or to addressing those who hold such negative perspectives can be especially helpful. Taken together, these suggested interventions provide guidelines for growth mindset applications among trainers, coaches, leaders, and educators.

\section{Implications for HRD Research}

Mindset theory literature, with its roots in implicit person theories introduced by Dweck and Leggett (1988) illuminates motivation and goal orientation. This research tradition is highly pertinent and has the capacity to enrich HRD research. The literature included in this scoping review, which originates from a variety of fields, is united through the intention to improve individual and group performance as well as to advance creative and innovative processes.

As is the case with many successful theories, researchers have sought to expand mindset theory beyond motivation and goal orientation toward learning to encompass creativity (for individuals) and an "organizational mindset" (Hanson et al., 2016; Özduran \& Tanova, 2017) in addition to other conceptualizations of mindset. While we have included several of these theoretical expansions in our scoping review as they met our inclusion criteria, there were others that were not included. Even though these excluded studies used terminology similar to mindset (e.g. global mindset or team mindset) these alternative applications are describing a state of mind and not beliefs about one's own or another person's human traits as established as implicit person theories by Dweck and colleagues (e.g. Chiu et al., 1997; Dweck, 2006; Dweck \& Leggett, 1988; Elliott \& Dweck, 1988). Thus, we recommend that HRD researchers expanding mindset theory in our field ground their research in a line of inquiry drawing on these foundational works.

Not only do we recommend rooting HRD research in a conceptual framework consistent with the mindset theory research lineage, we also argue for rigorous explanations in the methods section so that future researchers can replicate the results, including details on instruments, procedures of experiments, and modified scales, for example. Given recent critique of social science research and the lack of transparency surrounding research methods (Benjamin et al., 2018; Devlin, 2018), published studies with scant methods detail (including some research we reviewed for this study) are of concern even if the findings offered are thought provoking. In addition, we found that scholars have been modifying Dweck's growth and fixed mindset scale (2006) to fit their research context without providing rationale as to why they have changed the scales, which would be useful for future discussions.

With these cautions regarding conceptual framework and methods, we encourage HRD researchers to expand growth mindset research as there remains a narrowness to the literature beyond traditional educational settings. While findings are being extended to workplace learning and performance, more studies should be conducted outside universities, 
This is an author-produced, peer-reviewed version of this article. The final, definitive version of this document can be found online at Human Resource Development Review, published by SAGE. Copyright restrictions may apply. doi: 10.1177/1534484320939739

examining employees' and managers' mindsets, mainly focusing on the HRD field. Geographically, two-thirds of the research included in this study were conducted outside the U.S.A., which suggests there is a growing interest in mindset theory internationally and an opportunity for cross-cultural studies and those including diverse populations.

While individual-level outcomes and dyadic-level mindset research is expanding with HRD related outcomes, minimal research has focused on mindset theory at the team-level or organizational-level. Findings from several studies have potential implications for individual mindsets and their impact on the underlying dynamics of a team (e.g. Hanson et al., 2016; Özduran, \& Tanova, 2017; Wang et al., 2018). For example, studies illustrate the importance of team members' belief in others as they expose the way that one individual's beliefs about a person's general ability to grow or change and their likelihood to view another person's ability in a similar manner (Gutshall, 2013; Özduran, \& Tanova, 2017). On a larger scale, these recent studies are contributing to a growing literature base discussing organizational mindset (Hanson et al., 2016), which extends the basic premise of seeing organizational identity and characteristics as flexible and capable of dynamic development. Fueling this body of literature are studies that consider the way that one individual's mindset may play into the mindset of others. These studies suggest a relationship between individual and collective mindsets, or team mindset, that deserves careful inquiry.

Together, the studies in this literature review underscore the idea that changing human attributes, individually and collectively, is a function of HRD that is essential to create and sustain a learning organization.

\section{Limitations and Future HRD Research Suggestion}

Limitations of this study lead to further research suggestions. As we discussed above, we framed our scoping review by searching the term "growth mindset" given its increasing ubiquity in the common press. We were interested to analyze the body of empirical research focusing on growth mindset in workplace learning and HRD. This decision, however, presents a limitation, as some researchers have continued to expand upon Dweck's research using "implicit person theory" as a keyword in the scholarly literature. Among the research included for this study, we found that research studies using the phrase implicit [person] theories also used the phrase growth mindset. It is possible that our review, despite efforts to be inclusive, missed research that did not use the phrase "growth mindset."

During our research, of the 177 articles that met our initial search criteria, 30\% of the articles were excluded because the research participants were college students. We note, however, that the findings from this body of excluded studies can provide valuable insights to the HRD research community. For example, HRD related outcomes include learning performance improvement (Aditomo, 2015; Pennington \& Heim, 2016), learning from feedback (Forsythe \& Johnson, 2017; Lee et al., 2012), and life satisfaction with reduced stress (Lindsay, Kirby, Dluzewska, \& Campbell, 2015; Waithaka, Furniss, \& Gitimu, 2017). While these studies were excluded, they may inform methods or interventions that could be replicated in HRD settings. We also recommend that HRD researchers continue exploring the effects of diversity and culture on individual mindsets. While this review did reveal research studies with participants drawn from diverse contexts (e.g. Rattan \& Dweck, 2018; Shapcott \& Carr, 2019), those authors did not endeavor to conduct a cross-cultural comparison of their findings.

\section{Conclusion}

The studies that we have synthesized above reinforce the idea that one person's mindset can impact others in an organization. HRD outcomes, such as work engagement, coaching, and organizational citizenship behaviors, as demonstrated above, are furthered by a growth mindset. As we have illustrated, cultivating growth mindsets for these specific outcomes can be systematically implemented through continuous multilevel HRD interventions. This scoping review has demonstrated that mindset research is rapidly expanding into workplaces and its impact is significant in many fields, including HRD. Although we focused intentionally on empirical studies so that we could provide a strong evidence-base for integrating mindset research from its roots in psychology into HRD, there are many more articles and practical applications of the mindset research tradition that can also support the continuing expansion of mindset into HRD. 
This is an author-produced, peer-reviewed version of this article. The final, definitive version of this document can be found online at Human Resource Development Review, published by SAGE. Copyright restrictions may apply. doi: 10.1177/1534484320939739

\section{References}

*Studies included in the scoping literature review.

Aditomo, A. (2015). Students' response to academic setback: 'Growth mindset' as a buffer against demotivation. International Journal of Educational Psychology, 4(2), 198-222. https://doi.org/10.17583/ijep.2015.1482

Aronson, J., Fried, C. B., \& Good, C. (2002). Reducing the effects of stereotype threat on African American students by shaping theories of intelligence. Journal of Experimental Social Psychology (38), 113-125. https://doi.org/10.1006/jesp.2001.1491

Barrie, J. A., \& Pace, R. W. (1999). Learning and performance: Just the end of the beginning-A rejoinder to Kuchinke. Human Resource Development Quarterly, 10(3), 293-296.

Benjamin, D. J., Berger, J. O., Johannesson, M., Nosek, B. A., Wagenmakers, E. J., Berk, R. . . Johnson, V. E. (2018). Redefine statistical significance. Nature Human Behaviour, 2(1), 6-10. https://doi.org/10.1038/s41562-017-0189-z

Blackwell, L. S., Trzesniewski, K. H., \& Dweck, C. S. (2007). Implicit theories of intelligence predict achievement across an adolescent transition: A longitudinal study and an intervention. Child development, 78(1), 246263. https://doi.org/10.1111/j.1467-8624.2007.00995.x

*Caniëls, M. C., Semeijn, J. H., \& Renders, I. H. (2018). Mind the mindset! The interaction of proactive personality, transformational leadership and growth mindset for engagement at work. Career Development International, 23(1), 48-66. https://doi.org/10.1108/CDI-11-2016-0194

Chiu, C., Hong, Y., \& Dweck, C. S. (1997). Lay dispositionism and implicit theories of personality. Journal of Personality and Social Psychology, 73(1), 19-30. http://doi.org/10.1037/0022-3514.73.1.19

*Cutumisu, M., Brown, M. R., Fray, C., \& Schmölzer, G. M. (2018). Growth mindset moderates the effect of the neonatal resuscitation program on performance in a computer-based game training simulation. Frontiers in Pediatrics, 6, 1-10. https://doi.org/10.3389/fped.2018.00195

Day, D. V., \& Harrison, M. M. (2007). A multilevel, identity-based approach to leadership development. Human Resource Management Review, 17(4), 360-373.

Devlin, H. (2018, 27 August). Attempt to replicate major social scientific findings of past decade fails. The Guardian. Retrieved from https://www.theguardian.com/science/2018/aug/27/attempt-to-replicate-majorsocial-scientific-findings-of-past-decade-fails

Dweck, C. S. (2006). Mindset: The new psychology of success. New York: Ballantine.

Dweck, C. S. (2012). Mindsets and human nature: Promoting change in the Middle East, the schoolyard, the racial divide, and willpower. The American Psychologist, 67, 8, 614-22. http://doi.org/10.1037/a0029783

Dweck, C. (2014, November). The power of believing that you can improve [Video file]. Retrieved from https://www.ted.com/talks/carol_dweck_the_power_of_believing_that_you_can_improve?utm_campaign=t edspread\&utm_medium=referral\&utm_source=tedcomshare.

Dweck, C. S. (2000). Self-theories: Their role in motivation, personality, and development. Philadelphia, PA: Psychology Press.

Dweck, C. S., \& Leggett, E. L. (1988). A social-cognitive approach to motivation and personality. Psychological Review, 95(2), 256-273.

Dweck, C. S., Murphy, M., Chatman, J., Kray, L., \& Delaney, S. (2014a). Why fostering a growth mindset in organizations matters. Retrieved from http://knowledge.senndelaney.com/docs/thought_papers/pdf/stanford_agilitystudy_hart.pdf

Dweck, C. S., Walton, G., \& Cohen, G. L. (2014b). Academic tenacity: Mindsets and skills that promote long-term learning. Retrieved from https://ed.stanford.edu/sites/default/files/manual/dweck-walton-cohen-2014.pdf

Elliott, E. S., \& Dweck, C. S. (1988). Goals: An approach to motivation and achievement. Journal of Personality and Social Psychology, 54(1), 5-12. https://doi:10.1037/0022-3514.54.1.5

Forsythe, A., \& Johnson, S. (2017). Thanks, but no-thanks for the feedback. Assessment \& Evaluation in Higher Education, 42(6), 850-859. https://doi.org/10.1080/02602938.2016.1202190

French, R. P. II. (2016). The fuzziness of mindsets: Divergent conceptualizations and characterizations of mindset theory and praxis. International Journal of Organizational Analysis, 24(4), 673-691. https://doi.org/10.1108/IJOA-09-2014-0797

Garcia, S. K. (2007). Developing social network propositions to explain large-group intervention theory and practice. Advances in Developing Human Resources, 9(3), 341-358. https:/doi:10.1177/1523422307304100

Gregory, J. B., \& Levy, P. E. (2011). It's not me, it's you: A multilevel examination of variables that impact employee coaching relationships. Consulting Psychology Journal: Practice and Research, 63(2), 67-88. https://doi:10.1037/a0024152 
This is an author-produced, peer-reviewed version of this article. The final, definitive version of this document can be found online at Human Resource Development Review, published by SAGE. Copyright restrictions may apply. doi: 10.1177/1534484320939739

*Gutshall, C. A. (2013). Teachers' mindsets for students with and without disabilities. Psychology in the Schools, 50, 10, 1073-1083. https://doi.org/10.1002/pits.21725

*Hanson, J., Bangert, A., \& Ruff, W. (2016). Exploring the relationship between school growth mindset and organizational learning variables: Implications for multicultural education. Journal of Educational Issues, 2(2), 222-243. http://dx.doi.org/10.5296/jei.v2i2.10075

Hass, R. W., Katz-Buonincontro, J., \& Reiter-Palmon, R. (2016). Disentangling creative mindsets from creative self-efficacy and creative identity: Do people hold fixed and growth theories of creativity. Psychology of Aesthetics, Creativity, and the Arts, 10, 4, 436-446. http://doi.org/10.1037/aca0000081

Heslin, P. A., Latham, G. P., \& VandeWalle, D. (2005). The effect of implicit person theory on performance appraisals. Journal of Applied Psychology, 90(5), 842-856. https://doi:10.1037/0021-9010.90.5.842

*Heslin, P. A., \& VandeWalle, D. (2008). Managers' implicit assumptions about personnel. Current Directions in Psychological Science, 17, 3, 219-223. https://doi.org/10.1111/j.1467-8721.2008.00578.x

Hüther, G. (2016). Brainwash — Innovation starts in the mind. Developing Leaders, 23, 38-42.

Ismail, H. N. (2016). Training and organizational commitment: Exploring the moderating role of goal orientation in the Lebanese context. Human Resource Development International, 19(2), 152-177. https://doi.org/10.1080/13678868.2015.1118220

Kam, C., Risavy, S. D., Perunovic, E., \& Plant, L. (2014). Do subordinates formulate an impression of their manager's implicit person theory? Applied Psychology: An International Review, 63(2), 267-299. https://doi.org/10.1111/j.1464-0597.2012.00521.x

*Karwowski, M., Czerwonka, M., Lebuda, I., Jankowska, D. M., \& Gajda, A. (2019). Does thinking about Einstein make people entity theorists? Examining the malleability of creative mindsets. Psychology of Aesthetics, Creativity, and the Arts. http://dx.doi.org/10.1037/aca0000226

Keating, L. A., \& Heslin, P. A. (2015). The potential role of mindsets in unleashing employee engagement. Human Resource Management Review, 25(4), 329-341. https://doi.org/0.1016/j.hrmr.2015.01.008

*Keena, L., \& Simmons, C. (2015). Rethink, reform, reenter: An entrepreneurial approach to prison programming. International Journal of Offender Therapy and Comparative Criminology, 59(8), 837-854. https://doi.org/10.1177/0306624X14523077

Knowles, M. S. (1970). The Modern Practice of Adult Education; Andragogy versus Pedagogy. New York, NY: The Association

Kuchinke, K. P. (1998). Moving beyond the dualism of performance versus learning: A response to Barrie and Pace. Human Resource Development Quarterly, 9(4), 377-384.

Moon, K. H., Choi, K. B., \& Jung, S. J. (2012). Previous international experience, cross-cultural training, and expatriates' cross-cultural adjustment: Effects of cultural intelligence and goal orientation. Human Resource Development Quarterly, 23(3), 285-330. https://doi.org/10.1002/hrdq.21131

Lee, Y. H., Heeter, C., Magerko, B., \& Medler, B. (2012). Gaming mindsets: Implicit theories in serious game learning. Cyberpsychology, Behavior and Social Networking, 15, 4, 190-194. https://doi.org/10.1089/cyber.2011.0328

Levy, S. R., Stroessner, S. J., \& Dweck, C. S. (1998). Stereotype formation and endorsement: The role of implicit theories. Journal of Personality and Social Psychology, 74(6), 1421-1436.

Lindsay, K., Kirby, D., Dluzewska, T., \& Campbell, S. (2015). 'Oh, the places you'll go!’: Newcastle Law School's partnership interventions for well-being in first year law. Journal of Learning Design, 8, 2, 11-21. Retrieved from https://files.eric.ed.gov/fulltext/EJ1074672.pdf

McLagan, P. (1989). Models for HRD practice. Training and Development Journal, 43(9), 49-59.

Merriam, S. B., \& Bierema, L. L. (2013). Adult Learning: Linking Theory and Practice [eBook]. San Francisco, CA: Jossey-Bass.

Ong, C. H. (2014). Goal orientation of adult students towards learning strategies: The Malaysian context. Psychological Thought, 7(2), 156-167. https://doi.org/10.5964/psyct.v7i2.114

*Özduran, A., \& Tanova, C. (2017). Manager mindsets and employee organizational citizenship behaviours. International Journal of Contemporary Hospitality Management, 29(1), 589-606. https://doi.org/10.1108/IJCHM-03-2016-0141

Pennington, C. R., \& Heim, D. (2016). Creating a critical mass eliminates the effects of stereotype threat on women's mathematical performance. British Journal of Educational Psychology, 86, 3, 353-368. https://doi.org/10.1111/bjep.12110

*Rattan, A., \& Dweck, C. S. (2018). What happens after prejudice is confronted in the workplace? How mindsets affect minorities' and women's outlook on future social relations. Journal of Applied Psychology, 103(6), 676-687. http://dx.doi.org/10.1037/apl0000287 
This is an author-produced, peer-reviewed version of this article. The final, definitive version of this document can be found online at Human Resource Development Review, published by SAGE. Copyright restrictions may apply. doi: 10.1177/1534484320939739

Ravenscroft, S. P., Waymire, T. R., \& West, T. D. (2012). Accounting students' metacognition: The association of performance, calibration error, and mindset. Issues in Accounting Education, 27, 3, 707-732. https://doi.org/10.2308/iace-50148

Rumrill, P. D., Fitzgerald, S. M., \& Merchant, W. R. (2010). Using scoping literature reviews as a means of understanding and interpreting existing literature. Work, 35(3), 399-404.

*Shapcott, S., \& Carr, S. (2019). Golf coaches’ mindsets about recreational golfers: Gendered golf experiences start on the practice tee. Motivation Science. http://dx.doi.org/10.1037/mot0000154

Swanson, R. A. (2001). Human resource development and its underlying theory. Human Resource Development International, 4(3), 299-312. https://doi.org/10.1080/13678860110059311

Tabernero, C., \& Wood, R. E. (1999). Implicit theories versus the social construal of ability in self-regulation and performance on a complex task. Organizational Behavior and Human Decision Processes, 78(2), 104-127.

Tharenou, P., Saks, A. M., \& Moore, C. (2007). A review and critique of research on training and organizationallevel outcomes. Human Resource Management Review, 17(3), 251-273. https://doi.org/10.1016/j.hrmr.2007.07.004

Waithaka, A. G., Furniss, T. M., \& Gitimu, P. N. (2017). College student mind-set: Does student-parental relationship influence the student's mind-set? Research in Higher Education Journal, 32, 1-16. Retrieved from https://files.eric.ed.gov/fulltext/EJ1148938.pdf

*Wang, L., Owens, B. P., Li, J. J., \& Shi, L. (2018). Exploring the affective impact, boundary conditions, and antecedents of leader humility. Journal of Applied Psychology, 103(9), 1019-1038. http://dx.doi.org/10.1037/apl0000314

Werner, J., \& DeSimone, L. R. (2011). Human Resource Development (6 ${ }^{\text {th }}$ ed.). Mason, Ohio: Cengage Learning.Wood, R. E., Atkins, P., \& Tabernero, C. (2000). Self-efficacy and strategy on complex tasks. Applied Psychology: An International Review, 49(3), 430.

*Zeng, G., Chen, X., Cheung, H. Y., \& Peng, K. (2019). Teachers' growth mindset and work engagement in the Chinese educational context: Well-being and perseverance of effort as mediators. Frontiers in Psychology, 10, 1-10. https://doi.org/10.3389/fpsyg.2019.00839 